\title{
Arte-arquitetura no abandono
}

\author{
Rafael Ferreira de Souza \\ Graduado em Comunicaçáo Social pela Universidade Federal do Rio de Janeiro - ECO/UFRJ. Pós-graduado (Lato Sensu) em Política \\ e Planejamento Urbano pelo Instituto de Pesquisa e Planejamento Urbano e Regional - IPPUR/UFRJ. Mestrando em Arquitetura \\ e Urbanismo pelo Programa de Pós-graduaçáo em Arquitetura e Urbanismo da Universidade Federal Fluminense - PPGAU/UFF. \\ Contato: rafaeldeferreira@gmail.com
}

\section{RESUMO}

O presente artigo pretende discutir a linguagem contida na arquitetura abandonada e o potencial comunicativo originário de sua particular estética. Ponderando um olhar acerca da construçáo abandonada enquanto uma arte-arquitetura, pretendo compreender o espaço urbano e sua arquitetura como um painel fragmentado, um lugar que contempla uma linguagem não hegemônica, principalmente nas possibilidades de leitura e interpretação desse ambiente. $\mathrm{O}$ trabalho inicia-se com uma introdução, seguida por duas seções, a saber: (i) linguagem e a arquitetura abandonada; (ii) reflexôes sobre Berlim, e subsequentemente as consideraçóes finais. Ao propor um duplo viés do conceito arte-arquitetura, considero a arquitetura como um volume escultórico descontextualizado e paralelamente penso a arquitetura enquanto um painel de representaçóes de distintas artes visuais, sempre com uma abordagem de valoraçáo do espaço arquitetônico abandonado.

Palavras-chave: Abandono, arte-arquitetura, estética, subjetividade, cidade

\section{ABSTRACT}

The present article intends to discuss the language contained in the abandoned architecture and the communicative potential originating from its particular aesthetics. Pondering a look at abandoned construction as an art-architecture, I intend to understand urban space and its architecture as a fragmented panel, a place that contemplates non-hegemonic language, especially in the possibilities of reading and interpreting this environment. The work begins with an introduction, followed by two sections, namely: (i) language and abandoned architecture; (ii) reflections on Berlin, and subsequently the final considerations. When proposing a double bias of the concept of art-architecture, I consider architecture as a sculptural volume decontextualized and in parallel I think architecture as a panel of representations of different visual arts, always with an approach of valuation of the abandoned architectural space.

Keywords: Abandonment, art-architecture, aesthetics, subjectivity, city 


\section{Introduçáo}

Pensar a cidade em sua completude é uma tarefa árdua. Requer uma complexa trama conceitual onde nichos de conhecimentos se amalgamam no intuito de fornecer uma base teórica suficiente para engendrar um panorama plausível de entendimento. Porém, a cidade em sua essência se movimenta incessantemente em diferentes escalas, o que nos obriga a atar e reatar nossas ferramentas de leitura do espaço arquitetônico construído e de suas representaçóes simbólicas. Em um repertório que escapa a qualquer condicionante estática, onde respostas descomplicadas sirvam as turbulentas indagaçôes presentes neste palco de coexistência entre os indivíduos. Como ressalta Yi-Fu Tuan (1983, p.191): "A cidade é um lugar, um centro de significados, por excelência. Possui muitos símbolos bem visíveis. Mais ainda, a própria cidade é um símbolo".

Nesse ínterim, a cidade que se transmuta em um painel de bricolagem nos rebate sentidos e percepções que deslocam nossa subjetividade, trazendo à nossa vivência uma distinta estética, muitas das vezes renegada por sua intrínseca complexidade. "A cidade se faz obra inacabada porque excede, nos modos de apreensão que temos dela, o poder do sentido exercido pelos signos que não param de configurá-la" (JEUDY, 2005, p.118).

Portanto, ao tecer consideraçóes acerca da arquitetura abandonada presente na cidade, percebo que essas construçôes nos desafiam alçar a própria arquitetura para além de sua funcionalidade. É nesse ponto que um elo propositivo me permite interpretá-las por um viés conceitual de uma arte-arquitetura ${ }^{1}$ do abandono, não apenas por sua conformação, seu volume, mas também por servirem de palco para práticas artísticas registradas em seus destroços ${ }^{2}$ arquiteturais.

Inicialmente este artigo trará reflexôes que abarcam questóes concernentes à linguagem da arquitetura abandonada e suas nuances comunicacionais, através de uma amálgama de autores de searas distintas do conhecimento científico. Num segundo momento será explorado o caso da cidade de Berlim como exemplo emblemático dos conceitos e argumentos expostos no trabalho.

\section{Linguagem e a arquitetura abandonada}

Ao se considerar certas arquiteturas da cidade como obras de arte - ou como proposto nesse artigo uma delineação enquanto arte-arquitetura - é necessário que se faça uma aproximação do objeto de análise a partir de uma perspectiva distinta do costume. Uma forma peculiar de buscar um entendimento dos símbolos inclusos nos lugares e de seus elementos fundamentais: a arquitetura e o urbanismo. "Podemos, é claro, estudar arte cientificamente, mas tal investigação não substitui o que o próprio sistema de símbolos alcança." (NORBERG-SCHULZ, 1988, p.20. Tradução nossa).

Analisando especificamente os lugares e suas arquiteturas abandonadas, percebe-se uma vinculaçáo indissolúvel entre seus significados e suas linguagens inerentes, que comunicam uma ruptura na leitura e na assimilação desses ambientes edificados. “(...) o conceito de lugar mostra que deveria possuir uma 'estrutura imagética' que oferece ricas possibilidades de identificação" (Ibid., p.37). Essa rachadura interpretativa nos permite alocar em seu âmago uma base 
conceitual do abandono enquanto arte, portanto, capacitando à arquitetura esboçar uma nova semântica, não habitual, na conformação dos lugares da urbe.

O semiólogo e filósofo francês Roland Barthes (19151980) elaborou alguns estudos que versavam sobre a semântica do urbanismo e da cidade, de suma importância para o entendimento das sintaxes e dos signos contidos na urbe. Em um de seus textos ele diz:

Neste esforço de abordagem semântica da cidade, devemos tentar compreender o jogo dos signos, compreender que qualquer cidade é uma estrutura, mas que nunca se deve tentar, mas que nunca se deve querer preencher essa estrutura. Pois a cidade é um poema (...). É um poema que expande o significante, e é essa expansão que finalmente a semiologia da cidade deveria tentar captar e fazer cantar (BARTHES, 2001, p. 231).

Seus pensamentos e reflexóes apontam para os signos contidos nas leituras que se faz ao percorrer a cidade e para além, da necessidade de se fazer sentir uma necessidade plural de compreensão de sua linguagem, numa justaposição latente na experiência vivida da cidade. E novamente Barthes (2001) nos elucida: “(...) quem se desloca na cidade, isto é, o usuário da cidade (o que todos nós somos), é uma espécie de leitor que, segundo as suas obrigaçôes e os seus deslocamentos, recolhe fragmentos do enunciado para atualizá-los em segredo" (Ibid., p.228).

Nesse contexto, compete ainda apontar pensamentos do autor húngaro Katar Varsányi (2011, p.21) ao relacionar a questão da linguagem textual com o abandono arquitetural na cidade: "Sua inter-relação funcional, seu status antiestrutural ambíguo, sua in- definição, cria a ilegibilidade do texto urbano" (Tradução nossa). E não obstante, o indício permanente da imbricada relação da arquitetura e de seus signos, que teóricos da disciplina ressaltaram: "Há um repertório de formas arquitetônicas convencionalizadas que funcionam como sinais, assim como as palavras" (BONTA, 1977, p.42. Tradução nossa).

Requerer uma arquitetura engessada ou mesmo uma cidade parasitária, seria não compreender a própria história da arte, da arquitetura e da cidade. A arquitetura sempre esteve imbuída de uma conotação artística, naturalmente pelo seu exercício constituído da prática do desenho como embrião da representação da forma. A confluência entre técnica e arte é tida como o pilar da disciplina, mas que contudo, se desdobra em um conjunto de interdisciplinaridades necessárias para a praxis e a assimilação desta atividade.

Entretanto, a arte se distingue da arquitetura. A arte geralmente não é pressionada por resultados de caráter funcional, mas a arquitetura sim. Isso impóe na prática construtiva e edilícia certo limite de proposiçóes estéticas, mesmo que em casos excepcionais, alguns arquitetos procuram transbordar esse engessamento formal da arquitetura e de sua tectônica ${ }^{3}$.

Como ressalta o suíço historiador da arte Heinrich Wölfflin (1864-1945), ao relacionar as características da pintura e da arquitetura com a tectônica:

A pintura pode, a arquitetura precisa ser tectônica. A pintura somente desenvolve seus valores próprios no momento em que se separa da tectônica; para a arquitetura, a supressão da estrutura tectônica significaria a negação de si mesma (WÖLFFLIN, 1984, p.163). 
Neste sentido procuro entender os edifícios abandonados neste vigente trabalho enquanto uma arte-arquitetura, que contemple uma abordagem em duas diferentes dimensóes. A primeira, destacando a própria arquitetura e o seu formato - o corpo da arquitetura - que se encontra desconfigurado, e portanto, tomando como base seu próprio volume, perspectiva e formato, como uma arte escultórica ipsis litteris.

Assim como aponta Tim Edensor:

Essas formas esculturais nascem da violência do colapso, dos efeitos da decadência e dos efeitos subsequentes da hibridização. $\mathrm{O}$ metal trançado sugere uma maleabilidade até agora esperada, um rastro de papelada compóe um esguicho de design colorido em um piso de concreto, máquinas isoladas e uma infinidade de objetos não identificáveis jazem inescrutáveis em todos os andares. Mesmo a mais simples das estruturas verticais - postes de iluminação, cercas, pilares — são dotadas de novas sugestôes quando se inclinam para o lado. Erupçóes de bolhas em gesso e concreto afundado criam calhas agradáveis, e plataformas de madeira criam ondas estáticas em pisos de lojas antigas (EDENSOR, 2005, p.321-322. Tradução nossa).

E ademais, corroborando essa propositiva, ao falar da arquitetura abandonada:

(...) não se parecem mais com uma obra arquitetônica, mas começam a parecer uma escultura específica, acidental e surrealista, como uma forma que surge devido a um processo de decadência e colapso. A falta de cuidado com o local causa tanto a perda da forma arquitetônica quanto a cor, fator muito importante para a experiência estética e sensitiva. (NIESZCZERZEWSKA, 2016, p.5. Tradução nossa)

Nas imagens a seguir temos uma deformação registrada em uma casa abandonada no bairro Fazenda Inglesa, na cidade de Petrópolis/RJ. Essa deformidade se torna uma nova representação da arquitetura, em que sua funcionalidade já não está garantida em primeiro plano e sim, uma nova linguagem ${ }^{4}$, onde seus signos e significados ampliam a possibilidade de entendimento ${ }^{5}$ dessa arte-arquitetura e de sua materialidade.

Mais uma vez, os escritos de Tim Edensor sugerem:

Além do aspecto reconfigurado de objetos separados, os padrôes de associação que emergem da combinação arbitrária de coisas atingem acordes peculiares de significado e suposição e transmitem qualidades estéticas não familiares $(\mathrm{Op}$. Cit., p.322).

Alhures, considero também as arquiteturas abandonadas como painel, suporte ou palco de atividades artíticas. Protagonizadas por atores interessados em expressar sua subjetividade nas paredes, nas fachadas, nas janelas ou em qualquer outra materialidade que se encontra destituída de sua funcionalidade em que foi concebida, o espaço arquitetônico se transforma em uma plataforma estética e, portanto, de comunicação.

Nas próximas imagens percebemos as paredes internas de uma casa abandonada na Estrada da Saudade, em Petrópolis/RJ, servindo de palco para a expressão artística de atores interessados em explorar suas potencialidades. 
Quando nos deparamos com estruturas abandonadas na cidade, percebemos uma fragmentação que compóe a estética e a imagem da urbe. Considero entâo, que o edifício abandonado enquanto uma arte-arquitetura emana um potencial comunicacional através de sua imagética, de sua linguagem e que, portanto, permite abrir novas paletas na percepçáo e interpretação 'não-normativa' das construçôes do ambiente urbano.

Nesse âmbito que concatena a conformação arquitetural e suas distintas linguagens, as palavras de Roland Barthes trazem novamente coerência ao desabrochar dos olhares múltiplos, imprescindíveis na interpretação dos ambientes urbanos:

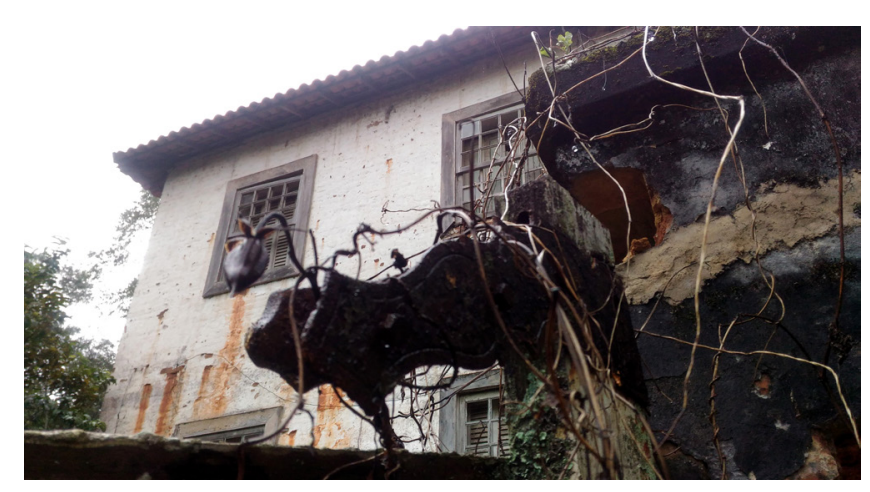

Figura 1: Detalhes de um antigo portão com a fachada lateral da casa abandonada em perspectiva.

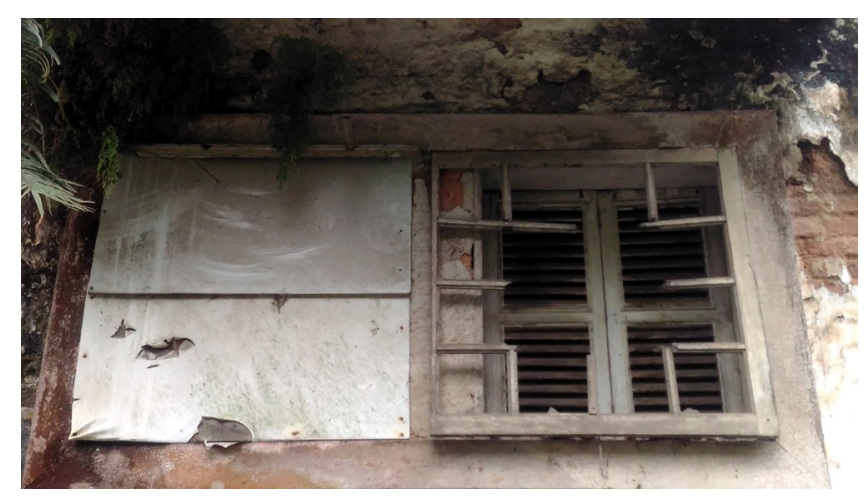

Figura 2: A janela já sem funçâo se torna uma composição abstrata com texturas e formas disparatas.
Falando sobre as leituras que fazemos dos símbolos da cidade (...) mas lembrando-nos sempre de que nunca se deve procurar fixar e tornar rígidos os significados das unidades descobertas, pois, historicamente, esses significados são extremamente imprecisos, recusáveis e indomáveis (BARTHES, 2001, p.231).

Esse movimento de compreender a arquitetura e a cidade enquanto linguagem ${ }^{6}$, sentido, comunicação e palavras, foi ressaltado em texto publicado pelos autores Depaule e Topalov, onde perfazem um interessante caminho analisando a importância das palavras que descrevem a cidade e suas relaçóes históricas com as sociedades e suas línguas.

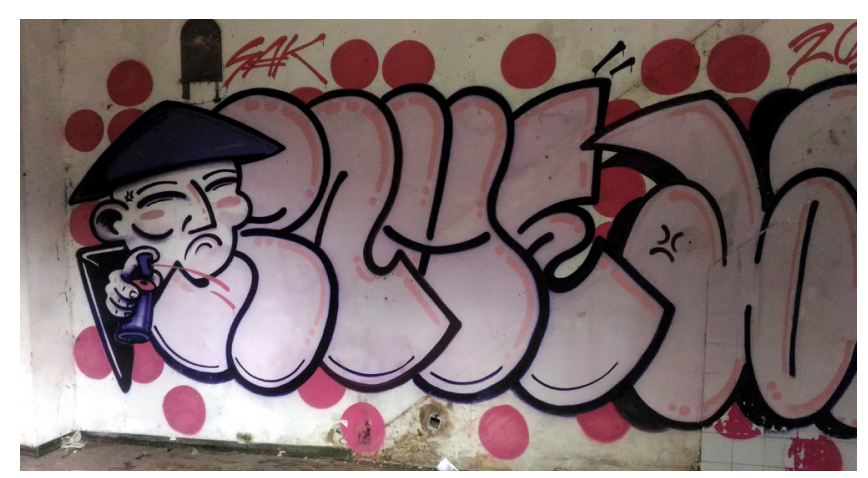

Figura 3: Pintura nas paredes internas da casa abandonada.

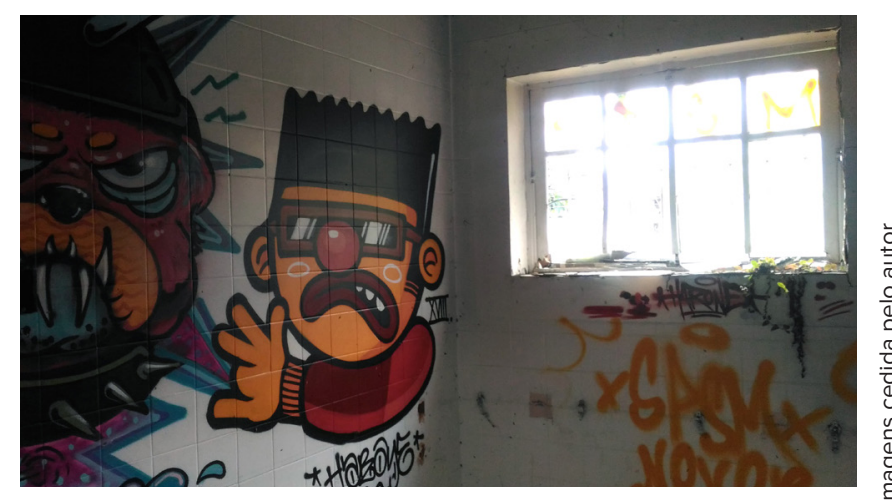

Figura 4: Grafites e desenhos em cômodo da casa abandonada. 
No entanto, mais importante ainda ao meu entendimento, seria a abordagem que é feita da significação e dos significados dos espaços da cidade: "Aideia, já abordada por Victor Hugo", de que a cidade é um livro aberto e de que seu espaço, uma espécie de linguagem ou de escrita, é familiar" (DEPAULE; TOPALOV, 2011, p.18). Estrutura essa, de certa forma, baseada em princípios da semiótica bastante propagada pelo autor e pesquisador italiano Umberto Eco (1932-2016). E ainda segundo os autores:

Inúmeras pesquisas, às vezes inspiradas em Greimas ou em Umberto Eco, que consideram o espaço como uma linguagem não-verbal (...). A escala que elas retiveram é, antes, aquela dos prédios, cujos elementos decompunham para identificar seus níveis de significação e extrair suas articulaçóes. Essa corrente suscitou igualmente uma abordagem "sintática do espaço construído, considerado do ponto de vista da materialidade de suas formas e das formas de sua materialidade", uma abordagem estrutural, situando-se apenas no plano dos significantes. Mas a semiótica, na escala da cidade, interessou-se e interessa-se também pela produção e pela leitura do sentido (Ibidem).

Assim sendo, a arquitetura abandonada carrega uma competência comunicacional e elucidativa que indica aberturas à diálogos que permeiam reflexôes entre $\mathrm{a}$ arte e a arquitetura. Fora dos limites tradicionais de disitinção entre suas respectivas especificidades, capacita-se uma resolução atípica do arquétipo de pré-concepção da materialidade arquitetural.

Destarte, possibilitando a permissão de uma estética que aventa uma transgressão dos limiares, e com isso, a licença para pensar o conceito exposto no termo deste estudo: a arte-arquitetura. E neste contexto, o enunciado contido na arquitetura capacita sua interpretação em plataformas atípicas:

Uma interpretação é o que faz a arquitetura parecer um trabalho cultural. A interpretaçáo pode assumir a forma de um documento escrito, um desenho, (...) um edifício em escala real, (...) e inúmeras outras formas. A noção de interpretação atende às múltiplas mídias da intelectualidade arquitetônica sem dar qualquer primazia. Pode-se dizer que não há língua materna para a comunicação arquitetônica (OTERO-PAILOS, 2010, p.23-24. Tradução nossa).

Essa arte-arquitetura se desvela e então através de sua linguagem nos noticia algo. Ao percebê-las em nossa cognição geram-se sentimentos distintos, abjetos, de desolação; causando assim como uma obra de arte, uma inquietação existencial proveniente de sua especificidade estética e de sua deformação, como ressalta o arquiteto finlandês Juhany Pallasmaa ${ }^{8}$ :

O inesperado e, em grande parte, inexplicável poder perceptual e emotivo da imagem artística me sugere que ela está profundamente arraigada em nossa historicidade biológica, no inconsciente coletivo e em nossa consciência existencial (PALLASMAA, 2013, p.12).

E ainda segundo o autor Henri-Pierre Jeudy:

As maneiras de apreensão da cidade têm a estranha faculdade de tirar proveito tanto do que satisfaz os gostos dos cidadãos quanto do que suscita sua repulsa. 
A feiúra faz do olhar um refém. (...) A feiúra, valendo por si mesma, passa a constituir prazer estético. (...) Assim, a percepçáo sensível de uma cidade, em suas mais diversas manifestações, assegura a legitimidade, a posteriori, de qualquer intervenção plástica. (...) Mesmo que uma torre tenha sido destruída (...), sua destruição seguida de sua ausência permaneceráo na memória dos citadinos (JEUDY, 2005, p. 82).

Esse discurso da linguagem arquitetônica abandonada trasncende as expectativas presentes em uma leitura linear do ambiente urbano. Essa quebra de paradigma serve de suporte para uma elaboração mais destrinchada da metáfora contida na semântica dos símbolos da cidade esquecida.

E segundo Roland Barthes:

A cidade é um discurso, e esse discurso é verdadeiramente uma linguagem: a cidade fala a seus habitantes, falamos nossa cidade, a cidade em que nos encontramos, habitando-a simplesmente, percorrendo-a, olhando-a. Entretanto, o problema é fazer surgir do estágio puramente metafórico uma expressão como "linguagem da cidade" (BARTHES, 2001, p.224).

Finalmente, considerando os pensamentos expostos sobre a semântica dos signos da arquitetura e de sua linguagem, é necessário alocar o conceito no debate que se depreende do campo linguístico e semiótico.
Apontamentos importantes para podermos posicionar a disciplina da arquitetura em conformidade com preceitos da perspectiva linguística e posteriormente dar continuidade a segunda seção do artigo:

As realidades do significado arquitetônico, passado e presente, podem ser colocadas em uma perspectiva inteligível somente se a perspectiva linguística estreita for abandonada e a visão mais ampla dos sistemas de significado for assumida. (...) Mas a própria teoria semiótica, como a prática arquitetônica, é um produto cultural. Teoria e prática interagem de maneiras mais complexas do que um observador ingênuo poderia supor (BONTA, 1977, p.77-78. Tradução nossa).

\section{Reflexóes sobre Berlim}

Para que se estampe uma ideia mais clara desse conceito, achei pertinente utilizar como exemplo a cidade alemã de Berlim. Esta nos serve como campo de reflexão, por conter alguns dos mais emblemáticos lugares abandonados.

Antes de proseguir, com intuito de costurar nossa base teórica, é importante sublinhar a necessidade de se extirpar a separação que se faz entre categorias pertencentes a seara da arquitetura e urbanismo enquanto ciência social aplicada. Acho sensato citar o historiador e teórico italiano Giulio Carlo Argan (1909-1992), quando este desenvolve uma reflexão sobre a essência da concepção dura do urbanismo: 


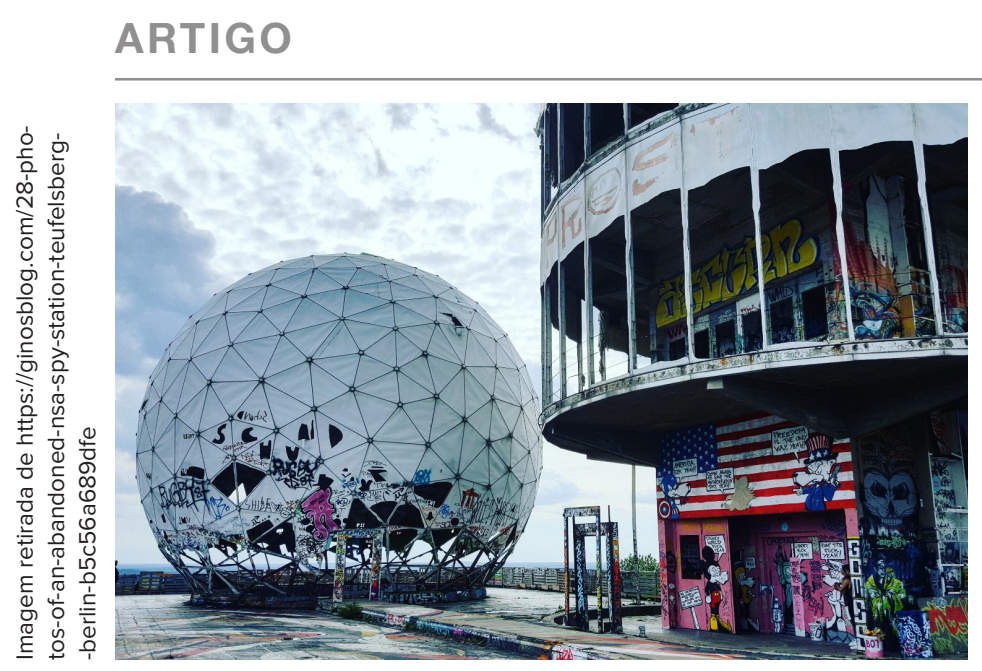

Figura 5: Cúpula e torre de espionagem da NSA.

A discussão sobre a essência do urbanismo, se é arte ou ciência, não tem sentido. Não tem sentido, porque a distinção e a oposição das categorias da arte e da ciência já não nos interessa. Pertence a um esquematismo cultural superado, não serve mais para esclarecer, mas apenas para confundir as ideias (ARGAN, 2005, p. 211).

Regressando as considerações sobre Berlim, verificamos que edifícios abandonados são presença frequente em pontos distintos da cidade. Nessa metrópole de pouco mais de três milhôes de habitantes, podemos nos confrontar com a arte-arquitetura do abandono a todo momento.

Alguns desses locais requerem uma investida mais minuciosa, onde a exploração urbana demanda desafios de acesso, como a conhecida Teufelsberg — montanha do diabo - onde se encontra abandonada uma antiga estação de espionagem da NSA? . Porém, na cidade também convivem outros espaços urbanos de mais fácil acesso como a Eisfabrik, e o atual centro cultural/moradia de squatters ${ }^{10}$ chamado Köpi, ambos localizados no bairro de Kreuzberg.

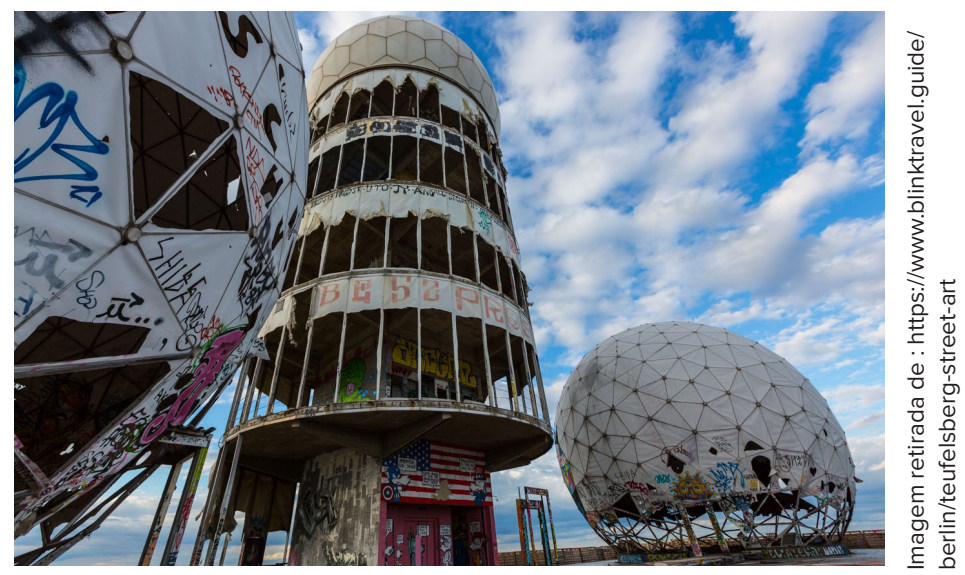

Figura 6: Teufelsberg - A abandonada montanha do diabo.

A respeito de Teufelsberg, Sarah Galvão ${ }^{11}$ nos diz:

Em 1950, Berlim estava sendo reconstruída e precisava de um lugar para colocar todos os restos da cidade destruída. Adivinha para onde eles foram? Teufelsberg. A montanha cresceu ainda mais e virou o ponto mais alto da cidade, ultrapassando inclusive as montanhas naturais de Berlim. Com isso, em 1961, os americanos decidiram instalar ali sua base da NSA (National Security Agency, a agência nacional de segurança) e Teufelsberg virou o ponto de escuta e espionagem do oeste para vigiar os comunistas do leste. Vários edifícios, com domos brancos no topo de cada um, foram construídos e hoje eles estáo abandonados e abertos ao público, depois de muita polêmica (GALVÃO, 2015. Online).

Ao se avistar as torres da NSA em Teufelsberg, a primeira impressão que temos é de estar em um local literalmente de outro planeta. A arquitetura, com cúpulas ovais brancas de material que lembram motivos da ciência espacial e dos cosmonautas, nos arre- 

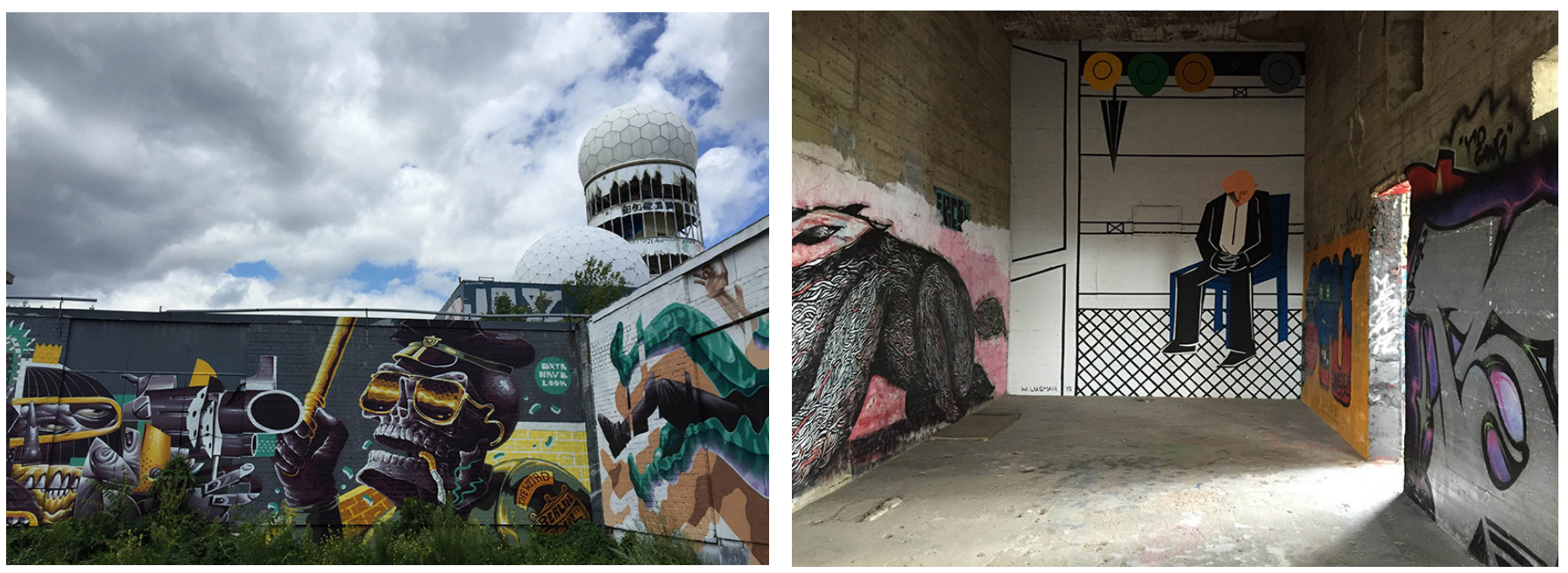

Figura 7 e 8: Artes visuais espalhadas pelos destroços da arquitetura de Teufelsberg.

bata com sua dimensão, pois afinal, era preciso estar acima de tudo para executar a espionagem através de ondas de rádio.

Com suas nuances estiradas por todos os lados, a torre se mantém ereta, porém contorcida por anos de abandono, formando uma estética peculiar de uma arte-arquitetura lapidada pelo tempo, um vulto escultórico. Em seu arredor, inúmeros cômodos e locais destinados previamente a caixa de máquinas, se encontram em estado extremo de deterioração. No entanto, ao longo dessa destruição em diversos pavimentos de acesso, grafites, pinturas e esculturas feitas com restos do local, preenchem esse espaço delapidado. Essa arte ${ }^{12}$ interna comunica um novo uso social do espaço arquitetônico em transição, uso este realizado pelos exploradores urbanos ${ }^{13}$ interessados em lugares abandonados, também conhecidos como urbexers.

Portanto esse local, ao meu entendimento, atua em duas dimensôes da arte-arquitetura. Uma que contempla a própria arquitetura e seu formato enquan- to uma obra de arte, atuando como uma escultura descontextualizada, e a segunda, onde a arquitetura se transforma em um painel, uma plataforma para registro de ideias e criaçôes visuais das mais distintas. Alterando assim a sua insinuação temporal que conflui nas referências de sua extinta funcionalidade e de seu atual ofício.

Nesse sentido é sensato salientar:

Os edifícios abandonados são atemporais, porque são inúteis. Eles são multitemporais, porque são o acúmulo de muitos 'momentos assincrônicos'. A experiência estética e corporal não é linear neste caso (NIESZCZERZEWSKA, 2016, p.5. Tradução nossa).

Com o mesmo viés de entendimento, a antiga fábrica de gelo - Eisfabrik - e o atual centro cultural Köpi, possuem representatividade ambígua ao servir como uso de moradia para os squatters, bem como locais de produção de arte visuais e ao mesmo tempo de concertos de música, no caso do Köpi. Além 
desse panorama, esses locais compóe também a conformação arquitetural de seu entorno, estabelecendo uma presença inextinguível nessa parte da cidade de Berlim.

As próximas imagens trazem clareza às reflexôes empreendidas no estudo. Com sua mescla imbricada de elementos de abandono e arte visual transcritos na materialidade da arquitetura — que agora opera distinas funçóes das que previamente propostas quando de seu intuito projetivo - os exemplares citados do Köpi e da Eisfabrik, ilustram de forma objetiva nosso propósito de análise.

Por último, vale ressaltar o notório caso da antiga Kunsthaus Tacheles (1990-2012), um antigo prédio abandonado de proporções enormes em pleno bairro central de Mitte. Se algum local pudesse significar de forma emblemática todo o conceito pretendido de uma arte-arquitetura do abandono, esse seria certamente um lugar símbolo e sintomático, não só dos constrastes que formam uma cidade cosmopolita como Berlim, mas assim como, da subcultura que emerge das contradiçóes da amálgama de distintas realidades que coexistem.

Como aponta Taylor Lindsay ${ }^{14}$ :

Era uma utopia de artistas, uma instituição cultural, um ímã turístico: depois de mais de duas décadas na Oranienburger Straße, Tacheles foi fechada, os artistas foram expulsos. (...) Se você andasse pela Oranienburger Straße no Mitte em qualquer ponto entre 1990 e 2012, provavelmente teria notado uma estrutura comandante, embora desgrenhada, localizada a uma curta distância da sinagoga (LINDSAY, 2018, Online. Tradução nossa).
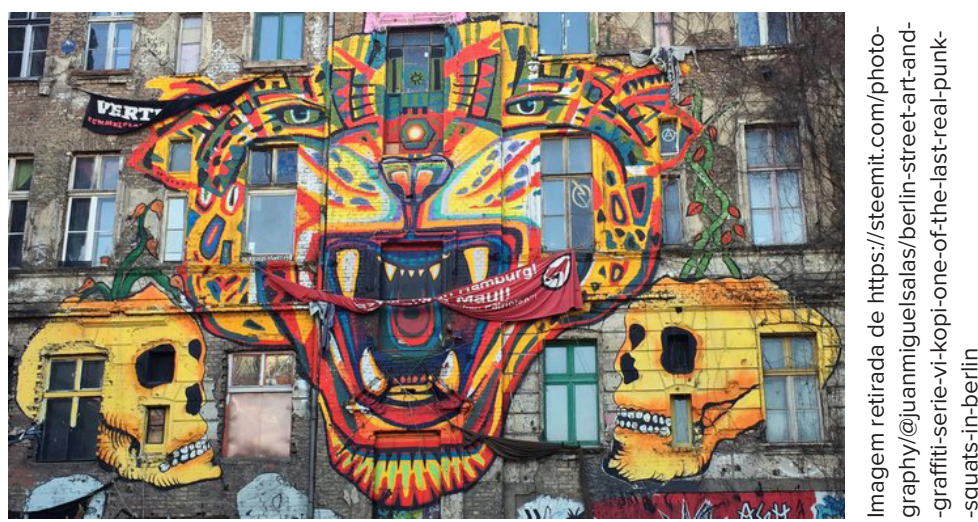

Figura 9: Arte gráfica estampada na fachada principal do edifício Köpi.

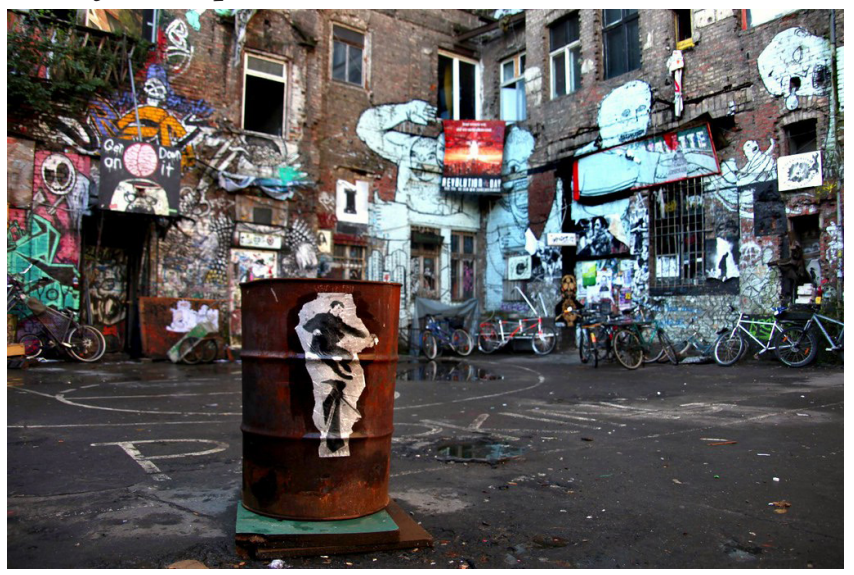

Figura 10: Pátio interno do Köpi repleto de artes visuais em distintos locais e objetos.

E ainda, segundo relatos de Guillaume Trotin ${ }^{15}$ :

(...) Tacheles é parte da ruína da guerra, parte da colônia de artistas, parte das maravilhas anárquicas e totalmente Berlim (...). Como um dos centros de arte independentes mais famosos de Berlim e uma das iniciativas artísticas mais notáveis, foi um local de interesse para todos os entusiastas da arte, independentemente das suas preferências. (...) Tacheles Art House, a icônica área de arte de Berlim que influenciou muito a percepção de Berlim como um dos principais locais de arte al- 
ternativa. (...) De monumentais pinturas murais nas paredes exteriores do edifício, ao impressionante jardim de esculturas em aço no pátio, escadas e corredores cheios de graffiti, cartazes e adesivos, a arte floresceu em todos os cantos do edifício ocupado. $\mathrm{E}$ não nos esqueçamos dos acontecimentos, performances e exposiçôes de tirar o fôlego, de ponta, hospedados dentro das paredes do edifício (TROTIN, 2016, Online. Tradução nossa).

Palco de múltiplas facetas expressivas, esses espaços abandonados promovem essa liberal e progressista forma de entender seu cunho cultural e conceitual. Sua estética e simbolismo flutuantes abrem rumos para leituras e usos de sua arquitetura e sua ordem material. Como aponta Tim Edensor (2005, p.323):

Ambas as justaposiçóes peculiares das coisas e os artefatos esculpidos contorcidos e deslocados encontrados em ruínas podem ter o efeito de tornar o mundo mais peculiar do que antes, especialmente após a reentrada no espaço urbano cotidiano. Esse surrealismo acidental torna a ordem material normativa menos óbvia, mais tênue e mais estranha do que aparentava anteriormente (Tradução nossa).

E, portanto, antes das consideraçóes finais, cabe aqui outra citaçáo acerca dessa presente ambivalência contida nos edifícios abandonados e em sua arquitetura:

(...) uma reflexão sobre a ambivalência de uma estética das ruínas contemporâneas. Prédios abandonados em ruínas funcionam também fora de tempo e fora de lugar. Sua ambivalência os situa em algum lugar entre a ruinofilia e a ruino-

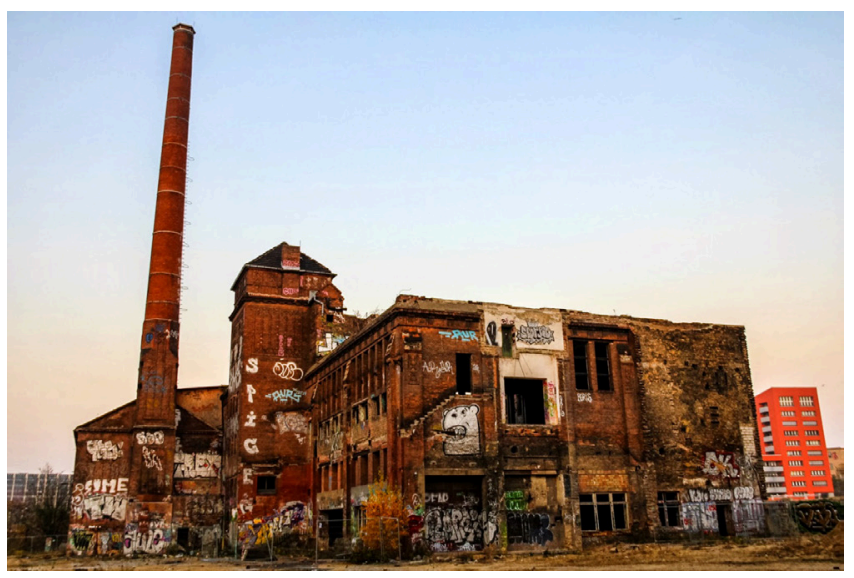

Figura 11: Panorama do prédio abandonado da Eisfabrik.

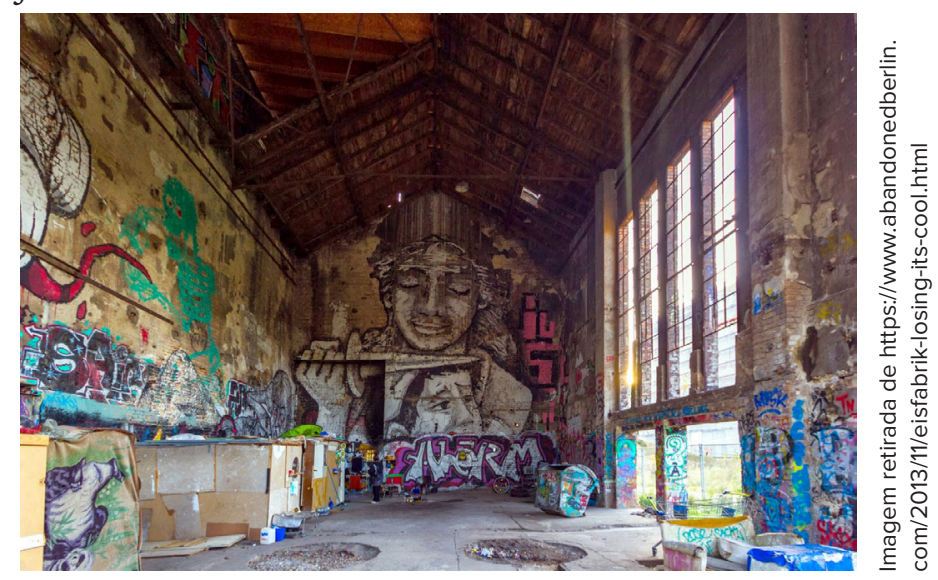

Figura 12: Interior da edifçio abandonado da Eisfabrik e seus registros artísticos.

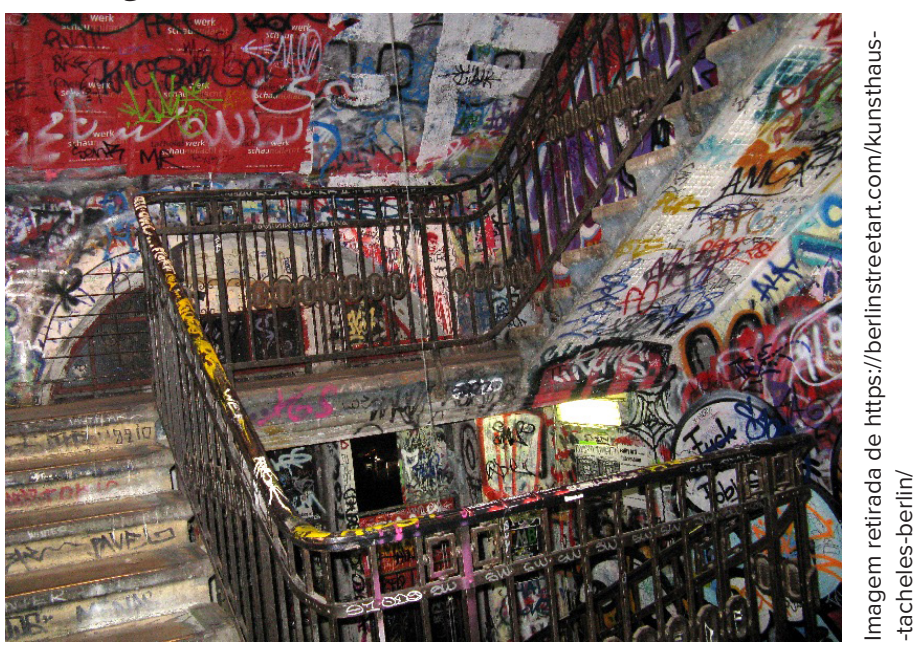

Figura 13: Escadas internas do edifício repleta de piches, grafites e pinturas. 
fobia no sentido social, entre determinadas formas de edifícios de onde saem e uma forma deformada de ruínas, e entre a dimensão multitemporal e atemporal de uma arquitetura abandonada (NIESZCZERZEWSKA, 2016, p.10. Tradução nossa).

Apresentadas aqui nossas consideraçôes sobre o abandono enquanto arte-arquitetura, será dado sequência ao trabalho através das consideraçóes finais.

\section{Consideraçóes Finais}

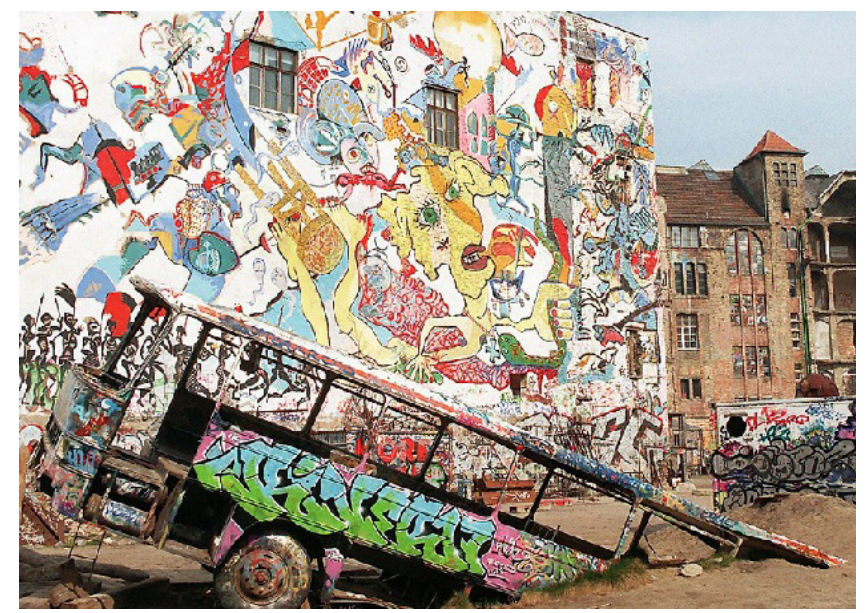

Figura 14: Pátio externo com o ônibus-escultura e artes gráficas na fachada lateral.

e interpretaçôes que possam servir de alento aos interessados em descobrir o significado dessa arquitetura da desolação que tanto vem capitaneando a atençáo de uma sociedade pós-industrial, que rasteja perante sua vicissitude indelével no espaço e no tempo.

A cidade de Berlim, na Alemanha, nos serviu como exemplo por conter um dos mais emblemáticos lugares abandonados da atualidade. Berlim, que é palco de uma contracultura vigorosa, parece se apropriar dos espaços arquitetônicos abandonados e em transição de maneira ímpar, o que proporcionou uma análise em consonância com os conceitos expostos no artigo.

Ao fim, a exploração urbana de lugares abandonados e o entendimento de suas arquiteturas abandonadas, podem suscitar mais indagaçôes do que respostas. A incessante tendência da cidade de se construir e de se desconstruir, desmoronando a insensata estética engessada, nos conduz com clareza à compreensão da premência de nos antevermos, e assim, deslocarmos 
nosso olhar acomodado com esquemas e estruturas estéreis, para o real espírito do lugar (NORBERG-SCHULZ, 1979), e de seus elementos constituintes. Nas palavras da autora Kate Nesbitt: “(...) genius loci, isto é, a ideia de espírito de um determinado lugar (que estabelece um elo com o sagrado), que cria um "outro" ou um oposto com o qual a humanidade deve defrontar a fim de habitar" (NESBITT, 2008, p.443).

Desconcertantes e grotescos, os cacos estilhaçados pela urbe asseguram a importância do debate e da reflexão, sem juízo de valor, dos lugares e de suas arquiteturas abandonadas.

\section{Notas de fim:}

1. Utilizarei o termo arte-arquitetura ao longo do texto com o intuito de pensar a arquitetura também como uma obra de arte. Tomarei como subentendido todas as vezes que for preciso citá-lo no presente trabalho.

2. Artistas como Gordon Matta-Clark, Bernd e Hilla Becher e Rachel Whiteread, têm em comum em seus trabalhos as temáticas de significado do vazio e do abandono e de uma temporalidade que esgota o valor e a utilidade dos objetos. Através de procedimentos artísticos transgressores e da construção de uma linguagem particular, esses artistas instigam a subversão de situações a princípio tidas como banais, sem importância e esteticamente desprezadas, causando o estranhamento de coisas anteriormente triviais.

3. O Museu Guggenheim Bilbao na Espanha é um bom exemplo dessa excepcionalidade projetiva realizada pelo arquiteto Frank Gehry.

4. Cf. TEPEDINO, 2016, p.46.

5. Cf. EDENSOR, 2005, p.330.
6. Cf. TEPEDINO, 2016, p.15

7. Victor Hugo (1802-1885) foi um dos maiores escritores românticos da França no século XIX, autor dos romances "Os Miseráveis" e "O Corcunda de Notre Dame", entre outras obras célebres. Fonte: PENSADOR. Biografia de Victor Hugo. (s.d.). Disponível em: <https://www. pensador.com/autor/victor_hugo/biografia/>. Acesso em: 17 jun. 2019.

8. Para além do contexto tratado neste capítulo, podemos pensar no impacto que a arte cinematográfica produz com suas imagens, como é o caso do filme Stalker do diretor Andrei Tarkovski, em que o cenário de fundo ao longo de quase todas as cenas são espaços abandonados. Fonte: TARKOVSKI, Andrei. Stalker. URSS, Leopardo Filmes. 1979. Disponível em: <https://www.youtube.com/watch?v=TGRDYpCmMcM>. Acesso em: 05 jun. 2018.

9. Sigla em inglês para: National Security Agency. Em português: Agência de Segurança Nacional dos Estados Unidos da América.

10. Pessoas que ocupam e moram de forma ilegal em prédios abandonados nas cidades.

11. GALVÃO, Sarah. Teufelsberg, a abandonada montanha do diabo em Berlim. (2015). Disponível em: <https:// chickenorpasta.com.br/2015/teufelsberg-a-abandonada-montanha-do-diabo-em-berlim>. Acesso em: 26 mar. 2019.

\section{Cf. GARRET, 2011, p.1065}

13. Para que possamos nos situar é válido apontar que no início da década de 1990 um movimento de exploração urbana, denominado Urbex começa a se engendrar de modo espontâneo. Desde entáo cada vez mais pessoas ao redor do planeta passaram a exercer essa prática lúdica de repensar a cidade através de incursóes em lugares abandonados - prédios, casas, localidades e cidades - como também em lugares e locais de infraestruturas (pontes, sistemas de esgoto e drenagem, entre outros) de difícil acesso, definidos pelo termo: 'off-limits'. 
14. LINSAY, Taylor. Life after Tacheles: What's become of the artist squatters? (2018). Disponível em: < http://www. exberliner.com/features/culture/life-after-tacheles/>. Acesso em: 22 mar. 2019.

15. TROTIN, Guillaume. The Story of Kunsthaus Tacheles - The Home of the Spirit of Art. (2016). Disponível em: $<$ https://berlinstreetart.com/kunsthaus-tacheles-berlin/>. Acesso em: 22 mar. 2019

\section{Referências Bibliográficas}

ARGAN, Giulio Carlo. História da arte como história da cidade. São Paulo: Martins Fontes, 2005, p. 210-250.

BARTHES, Roland. A aventura semiológica. São Paulo: Martins Fontes, 2001, p. 219-231.

BONTA, Juan Pablo. Sistemas de significacion em arquitectura. Barcelona: Editorial Gustavo Gili, S.A., 1977, p. 25-80.

DEPAULE, Jean-Charles; TOPALOV, Christian. A cidade através de suas palavras. In: Palavras da cidade. (Org.) Maria Stella Bresciani. Porto Alegre: UFRGS, 2011.

EDENSOR, Tim. Waste matter - the debris of industrial ruins and the disordering of the material world. In: Journal of Material Culture Vol. 10(3). Londres: SAGE Publications, 2005, p.311-332.

GALVÃO, Sarah. Teufelsberg, a abandonada montanha do diabo em Berlim. (2015). Disponível em: <https://chickenorpasta.com.br/2015/teufelsberg-a-abandonada-montanha-do-diabo-em-berlim>. Acesso em: 26 mar. 2019.

GARRET, Bradley L. Assaying history: creating temporal junctions through urban exploration. In: Environment and Planning D: Society and Space, volume 29, 2011, p.1048-1067.

JEUDY, Henri-Pierre. Espelho das cidades. Rio de Janeiro: Editora Casa da Palavra, 2005.

LINSAY, Taylor. Life after Tacheles: What's become of the artist squatters? (2018). Disponível em: < http://www. exberliner.com/features/culture/life-after-tacheles/>. Acesso em: 22 mar. 2019.

NESBITT, Kate (Org). Uma nova agenda para a arquite- tura: antologia teórica (1965-1995). São Paulo: Ed. Cosac Naify, $2^{\circ}$ edição rev., 2008.

NIESZCZERZEWSKA, Małgorzata. Derelict architecture: Aesthetics of an unaesthetic space. In: Revista Argument. Vol. 5 (2/2015). Cracóvia, 2016 (online), p. 387-397.

NORBERG-SCHULZ, Christian. Architecture: meaning and place: selected essays. New York: Electa/Rizzoli, 1988, p.7-48.

Christian. Genius loci: towards a phenomenology of architecture. New York: Rizzoli, 1979.

OTERO-PAILOS, Jorge. Architecture's Historical Turn: Phenomenology and the Rise of the Postmodern. Minneapolis: University of Minnesota Press, 2010.

PALLASMAA, Juhani. A imagem corporificada: imaginação e imaginário na arquitetura. Traduçáo por Alexandre Salvaterra. Porto Alegre: Bookman Editora Ltda, 2013.

PENSADOR. Biografia de Victor Hugo. (s.d.). Disponível em: <https://www.pensador.com/autor/victor_hugo/biografia/>. Acesso em: 17 jun. 2019.

TARKOVSKI, Andrei. Stalker. URSS, Leopardo Filmes. 1979. Disponível em: <https://www.youtube.com/watch?v=TGRDYpCmMcM>. Acesso em: 05 jun. 2018.

TEPEDINO, Alice Varella. Arquitetura entre matéria e sentido: Projeto, presença e crítica no campo ampliado da cultura contemporânea. 178p. Dissertação de Mestrado Departamento de Arquitetura e Urbanismo, Pontifícia Universidade Católica do Rio de Janeiro. Rio de Janeiro, 2016.

TROTIN, Guillaume. The Story of Kunsthaus Tacheles - The Home of the Spirit of Art. (2016). Disponível em: <https://berlinstreetart.com/kunsthaus-tacheles-berlin/>. Acesso em: 22 mar. 2019.

TUAN, Yi-Fu. Espaço e Lugar a perspectiva da experiência. São Paulo: Ed. DIFEL, 1983.

VARSÁNYI, Kata. The social life of ruins: urban exploration of abandoned spaces in Budapest. Dissertação de Mestrado da Universidade Central da Europa - Departamento de sociologia e antropologia social. Budapeste, 2011.

WÖLFFLIN, Heinrich. Conceitos fundamentais da história da arte. Tradução por João Azenha Jr. São Paulo: Martins Fontes, 1984. 